\title{
Por uma dialética das controvérsias: o fim do modelo positivista na história das ciências
}

GILDO MAGALHÃES ${ }^{I}$

Mas na história da ciência as coisas funcionam como na própria
ciência: é uma tarefa delicada a de selecionar e avaliar os fatos
"bons", aqueles que foram importantes, ou mesmo decisivos...

(Thuillier, 1994, p.25)

\section{Introdução}

1

HISTÓRIA da(s) ciência(s) apresenta uma problemática que, apesar de muito interessante, não tem sido em geral objeto de seus praticantes. Trata-se do papel das controvérsias, que ocorrem em dois planos distintos, mas interligados e a que recorreremos, ocasionalmente passando de um para outro: o das controvérsias dentro das ciências e o das controvérsias na sua historiografia.

As controvérsias científicas podem levar-nos a reexaminar as hipóteses e metodologias da história das ciências. Assim, a discussão dos historiadores da ciência sobre as informações que podem ser tiradas das fontes e as reflexões que já foram efetuadas a respeito de textos e suas narrações em geral têm a possibilidade de conduzir a novas abordagens de temas sobre os quais não se esperavam mais avanços. Com isso, ampliam-se as oportunidades para orientações metodológicas fecundas, narrativas mais inovadoras e um alargamento do interesse despertado pela história das ciências.

Vem crescendo a compreensão de que as controvérsias são tanto inevitáveis nas ciências quanto fundamentalmente benéficas. Realçar a história das ciências como história das controvérsias científicas apresenta o máximo interesse porque muitas dessas controvérsias do passado continuam extremamente atuais e, ao mesmo tempo, é um privilégio do conhecimento científico alimentar-se tanto de controvérsias quanto de ortodoxias. Algumas dessas controvérsias atuais incluem: a essência dos átomos e das chamadas "partículas"; a existência do éter luminoso; como se dá o surgimento de novas espécies biológicas e qual é a natureza da vida; a ressurreição do lamarckismo frente à ideologia darwinista; origem e dimensões do universo; formação e distribuição total dos elementos químicos; evolução do clima etc.

Saindo das ciências naturais, na história em geral está-se mais acostumado com as controvérsias que envolvem as fontes e suas interpretações, característica 
que não deixa de ser um reflexo da grande complexidade que cerca as ciências humanas. Talvez por isso, seja relativamente recente o renovado interesse das ciências naturais pela história das controvérsias em que estão envolvidas. De fato, estamos convictos de que uma maior atenção dada pelos historiadores às controvérsias científicas como sendo o primum movens do avanço desse conhecimento impactaria favoravelmente ambos os campos: conhecer melhor as características das ciências naturais e aprofundar a pesquisa do "passado das ciências como história" (na expressão de Gavroglu, 2007). Para esse objetivo é, porém, necessário ultrapassar certos problemas decorrentes da adoção, ainda que inconscientemente, da visão positivista da história das ciências e para isto apontaremos para uma possibilidade de solução.

No Brasil, ao contrário do que sucede no Hemisfério Norte e mesmo em alguns países latino-americanos (notadamente no México), não tem havido entre historiadores da ciência uma discussão continuada, com profundidade analítica e coerência sistemática, sobre controvérsias metodológicas e historiográficas próprias desse campo. Tal debate ocorreu entre nós muito brevemente no período inicial da implantação institucional da história das ciências na década de 1970 (e observamos de passagem, que este começo se deu no Departamento de História da USP), mas depois o que se observa em geral é uma escolha pessoal dos pesquisadores por uma determinada corrente metodológica, sem uma troca de opiniões a esse respeito. ${ }^{1}$

O tema das controvérsias, se ainda não recebe a devida atenção dos historiadores da ciência em geral, é tangenciado por alguns filósofos da ciência, que estão porém mais preocupados com questões internas de discurso e da lógica das controvérsias do que com seus fundamentos históricos. ${ }^{2}$ Todavia, o conhecido texto de Francis Bacon, O progresso do conbecimento (1605), já postula uma história do conhecimento que sirva menos para satisfazer a curiosidade do que para um desígnio de instruir os sábios para o uso do saber em meio a controvérsias. Foi dentro do programa baconiano que resultaram as primeiras obras de histórias de ciências particulares, que surgiram notadamente a partir do século XVIII. ${ }^{3}$

Ao trabalharmos com essas fontes precursoras numa pesquisa sobre a história do movimento filosófico-científico alemão chamado de Naturphilosophie, além de comprovar a força das controvérsias científicas, evidenciou-se a persistência das fontes metafísicas de problemas científicos, que não se restringem à era (mal considerada) do "romantismo" científico da Naturphilosophie, mas trazem contribuições para os fundamentos da ciência atual (Magalhães, 2017, p.153-238).

\section{A herança do positivismo e suas fraturas}

Em especial nos séculos XIX e XX despontou uma vertente, por alguns chamada de "estilo francês" de história das ciências, que se reveste de um caráter particularmente filosófico e crítico. Essa característica está presente na constitui- 
ção da história das ciências como disciplina autônoma e deve muito a Auguste Comte e seu Curso de Positivismo. Não negamos a importância fundamental de ideias positivistas nem examinaremos aqui algumas sutilezas desse pensamento sobre a história das ciências que escaparam a muitos de seus continuadores, mas registramos que Comte foi pioneiro ao demandar ao Collège de France em 1832 a criação de uma cátedra de "história geral das ciências". A proposta vingou apenas em 1892, quando um discípulo direto de Comte, Pierre Lafitte, tomou posse da nova cadeira (Braunstein, 2008).

No final do século XIX, os primeiros historiadores profissionais da ciência, como o francês Paul Tannery e o belga Georges Sarton, tinham em comum com essa base positivista quatro ideias programáticas, que foram tomadas como fundamentos da historiografia, mas que continham os germes que propiciam sua contestação, como comentado a seguir:

a) A ciência é a mais alta atividade humana e fazer sua história permite compreender melhor os avanços do espirito humano.

Que tipo de história seria feita nesse contexto? O modelo foi ditado pelo já citado Lafitte, ao discursar em 1892 na inauguração do curso geral de história das ciências, reafirmando sua crença de que chegara o momento em que a ciência deveria assumir a direção dos assuntos humanos. Essa perspectiva caminhava de par com sua insistência nos "grandes nomes" das ciências. Em decorrência, a sua será uma história "heroica", próxima da história de nomes e datas, traço ainda dominante na concepção de muita história que se escreve, centrada em "grandes vultos e suas façanhas" como Galileu, Newton, Darwin, Einstein e outros. ${ }^{4}$

b) A história das ciências não deve ser uma história das ciências particulares, mas uma "bistória geral", uma vez que as ciências se desenvolvem simultaneamente e sob a influência umas das outras.

Embora seja importante ressaltar a interdisciplinaridade das diversas ciências, a ambição de abrangência global acabou na prática dificultando sua execução, dado o crescimento desmesurado dos campos científicos e da capacitação necessária para se debruçar sobre todos eles, a não ser permanecendo num nível de elevada generalidade.

c) A história das ciências tem um viés politico e permite ultrapassar preconceitos nacionalistas e religiosos, pois acolhe a fé humanista no papel pacificador e internacionalista de que a própria ciência é portadora.

Essa audaciosa crença infelizmente vem sendo contínua e crescentemente contrariada pelo uso bélico da ciência. ${ }^{5}$

d) A história das ciências é evolucionista, no sentido de que não há revoluções cientificas, mas uma continuidade em que novas verdades absorvem as antigas, desenvolvendo-as.

Como entender, contudo, as transformações das ciências que, à primeira vista, parecem radicais, à luz da célebre fórmula positivista de que "o progresso 
nada mais é do que o desenvolvimento da ordem"? Julgamos que essas colocações evolucionistas ainda merecem discussão, pois suas contestações levam a posturas metodológicas interessantes. Assim entendida, a história das ciências não seria uma simples narração de fatos, mas "teria a finalidade de compreender o desenvolvimento do pensamento humano e a própria história da humanidade". ${ }^{6}$ Perceber, contudo, a história das ciências como um progresso contínuo e dogmático da razão é uma simplificação que pode não corresponder ao que se verifica. A visão linear de progresso do espírito humano, que seria atestada pela história das ciências, foi abalada por dois motivos principais, que se interpenetram: a Primeira Guerra Mundial trouxe o pessimismo tipicamente expresso por Oswald Spengler em sua história da decadência do Ocidente. Em segundo lugar, houve uma ruptura da ciência com o racionalismo, representado em especial pela mecânica quântica, cuja formulação altamente matematizada, mas insatisfatória porque não causal, se deu diretamente sob a influência do ambiente de pessimismo spengleriano da república de Weimar. ${ }^{7}$

A concepção positivista de ciência subsiste, com diferentes nuanças, mesmo nos dias atuais e é, possivelmente, o maior obstáculo para a apreciação da importância das controvérsias científicas na história, pois em sua perspectiva historiográfica os fatos científicos são vistos como brotando acriticamente e automaticamente das experiências levadas a cabo pelos cientistas. Pelo contrário, ao levantar uma série de casos históricos, verificamos a existência de um filtro das ideias condutoras previamente à observação da natureza e à realização das experiências científicas.

Destacamos que a prática de uma história das ciências de base positivista não favorece a posição ativista que foi citada de início: a de que a história da ciência seria essencial não só para entender seu desenvolvimento, mas porque levaria a melhor aprender e praticar ciência(s) - e especialmente numa época em que o aproveitamento escolar em ciências no Brasil é avaliado como tendo um padrão muito baixo, comparado com outros países, inclusive latino-americanos.

\section{Três vertentes de controvérsia historiográfica das ciências}

A comunidade de história da ciência até a década de 1920 teve um papel relevante para que, nesse período, fossem disponibilizados alguns instrumentos de trabalho fundamentais, tais como biografias, bibliografias, edições e traduções de obras científicas clássicas, revistas, sociedades e institutos ligados à academia. Entretanto, faltava se estabelecer ainda preceitos metodológicos e teóricos mais precisos. Efetivamente, foi o russo Alexandre Koyré quem propôs na década de 1930 alguns desses conceitos fundamentais, em meio a controvérsias que ainda dividem os historiadores. Escolhemos em particular três grandes querelas metodológicas, de que tratamos a seguir, devido à frequência com que elas comparecem na historiografia, mesmo quando não nomeadas.

\section{Externalismo e internalismo}

A controvérsia que opõe o externalismo contra o internalismo foi deflagra- 
da no II Congresso Internacional de História das Ciências, em Londres (1930), quando a delegação soviética, chefiada por Nikolai Bukharin, compareceu e apresentou, entre outras, uma comunicação de Boris Hessen com o título sugestivo de "As raízes sociais e econômicas dos Principia de Newton". ${ }^{8}$ Interpretando o mecanicismo newtoniano como uma expressão dos interesses da burguesia, Hessen concluía que os temas e técnicas de matemática estudados por Newton eram compatíveis com algo externo ao desenrolar da pesquisa científica em si: o desenvolvimento no século XVII de objetivos ligados à ascensão do capitalismo, tais como a navegação, os cálculos de balística naval e o projeto de bombas para esgotar a água nas escavações de mineração. Para Hessen, a filosofia de Newton foi limitada pela sua crença, que seria também burguesa, na natureza inerte da matéria, o que fez com que o sábio inglês recorresse à mão de Deus (o "relojoeiro", em sua famosa metáfora) para colocar o Sol e os corpos celestes em movimento.

A chamada "tese de Hessen", nome dado em referência a esse historiador e ligado à procura dos fundamentos de qualquer teoria científica não em sua lógica interna, mas externamente em fatores sociais e econômicos, não foi seguida à risca, a não ser por alguns cientistas que se tornaram conhecidos historiadores da ciência e eram membros do Partido Comunista Britânico, como o físico John Bernal, o bioquímico John Haldane e o embriologista Joseph Needham.

Este último se tornou um conhecido sinólogo e se dedicou nas seis décadas seguintes ao Congresso de Londres a estudar a ciência chinesa. Divulgou-se assim a controvérsia que ficou conhecida como "problema de Needham": por que a ciência moderna como a conhecemos foi criada na Europa e não na China, dado o grande desenvolvimento chinês em vários campos do conhecimento? A questão continua a ser intensamente debatida desde a resposta externalista dada pelo próprio Needham, de que apesar de a ciência chinesa ultrapassar a europeia até o Renascimento, a burocracia feudal da China menosprezava sua burguesia comercial, que permaneceu tímida e não impulsionou o desenvolvimento científico e técnico. O "problema" se tornou a "tese de Needham", segundo a qual a institucionalização da ciência dependeu da eclosão de um capitalismo pujante, como ocorreu no Ocidente. Trata-se de uma controvérsia historiográfica de grande porte, bastante difundida nos foros internacionais, pois discute como teria sido o desenvolvimento da ciência em outros continentes, fora da perspectiva eurocêntrica. $O$ problema de Needham quase não tem tido repercussão no Brasil, onde seria bem-vindo no debate sobre o advento tardio das relações capitalistas modernas e o baixo desempenho da ciência e da educação no país.

Pode-se considerar que a controvérsia lançada por Hessen também está na origem do doutorado do sociólogo Robert Merton. Em Ciência, tecnologia e sociedade na Inglaterra do século XVII, Merton explorou duas afirmativas externalistas, primeiramente sublinhando a importância dos técnicos e suas práticas no desenvolvimento da ciência clássica, como os marinheiros na determinação da longitude no mar ou na medição da declinação magnética das bússolas. Sua segunda conclusão, fortemente apoiada em Max Weber e que passou a ser co- 
nhecida como "tese de Merton", é que a ética protestante dos puritanos considerou a razão e a experiência exercitadas na ciência como meios independentes adequados para provar verdades religiosas. Para Merton, o puritanismo deu ênfase ao empirismo, ascetismo, livre exame e utilitarismo, que desempenharam um papel importante para o desenvolvimento científico. Seguiu-se então uma tradição de controvérsia historiográfica, pois essa tese recebeu fortes críticas desde sua publicação, inclusive em estudos posteriores que defenderam a contribuição dos católicos à ciência. ${ }^{9}$

Ainda dentro da controvérsia externalista, há que citar o trabalho que Edgar Zilsel apresentou no Congresso pela Unidade da Ciência (1939). Conhecido como "tese de Zilsel", mantém que o nascimento da ciência moderna ocorreu no Renascimento e se deveu à aproximação operada pelo incipiente capitalismo moderno entre três categorias, até então sem comunicação direta: universitários, humanistas e artesãos-engenheiros. ${ }^{10} \mathrm{~A}$ redescoberta dos trabalhos de Edgar Zilsel está na base dos estudos sobre os filósofos e as máquinas, feitos por Paolo Rossi e também nas narrativas recentes que dão um lugar privilegiado para os trabalhadores anônimos que participaram na história das ciências junto com os "grandes nomes".

Segundo a crítica de Koyré, a partir de seus Estudos Galilaicos (1939), explicações tão externalistas como as quatro teses mencionadas (de Hessen, Needham, Merton e Zilsel) teriam negligenciado dois fatores determinantes para o desenvolvimento da ciência: o interesse puramente teórico na matemática, ligado à redescoberta renascentista da ciência grega e o estudo continuado da astronomia, também estimulado mais pelo interesse teórico do que prático. Essa visão de Koyré, considerada por muitos como "internalista", defende que a ciência é antes de tudo theorein, a busca da verdade por meio do itinerarium mentis in veritatem, revelável pela história da ciência. ${ }^{11}$

Historiadores da ciência de orientação política conservadora têm atacado as explicações externalistas por sua aproximação ao marxismo. Quer nos parecer que, pelo contrário, a posição de Koyré em Do mundo fechado ao universo infinito ainda seria defensável e compatível com a proposta, que apresentaremos mais à frente, de uma dialética das controvérsias. Por um lado, é uma ilusão admitir uma ciência "pura" ou "neutra", fora de influências externas. ${ }^{12}$ Por outro lado, se para bem entender a história de um tópico científico é preciso adentrar a sua parte técnica ou "interna", por outro tem-se que incluir a ação forte de variáveis externalistas, não só por meio de influências socioeconômicas, mas também pela via da cultura que atua na contemporaneidade dos cientistas.

\section{Continuismo e descontinuísmo}

Uma segunda controvérsia separa os historiadores da ciência e que teria inicialmente oposto os praticantes de cultura francesa e os anglo-saxônicos, em torno da opção entre continuísmo ou descontinuísmo (ou ainda, em outro linguajar, ruptura, revolução). 
O grande nome a favor do continuísmo na fase profissionalizante no início do século XX foi o historiador francês Pierre Duhem, que adotou uma posição ativista com relação à ciência e não se furtou a emitir julgamentos acerca de seu valor epistemológico. Em estudos memoráveis sobre a origem da ciência, Duhem sustentou que a mecânica moderna deriva de uma série ininterrupta e lenta de aperfeiçoamentos de doutrinas professadas no seio da Idade Média, como a teoria do ímpeto e a geometria do contínuo matemático. Para ele, uma teoria, mais do que a função de explicar, atua para "salvar os fenômenos" (sózein ta phainómena), expressão grega com que se referia não só aos hábeis artifícios da astronomia ptolomaica, mas também às explicações dadas a respeito do heliocentrismo por Copérnico e Galileu.

A controvérsia se intensificou quando Gaston Bachelard, um filósofo conhecido por sua escrita particularmente poética, se opôs ao continuísmo de Duhem. Em seu O novo espírito científico (1934), Bachelard gestou as noções de "mutação intelectual" e "corte epistemológico", não no sentido de "revolução", mas ainda restritas para designar a ruptura entre o senso comum e o conhecimento científico. Seu discípulo Georges Canguilhem também investigou a tradição do continuísmo, levando-a ao próprio campo interno à ciência em seu doutorado, publicado como $O$ normal e o patológico, em que se pergunta se seria descontínua a transição entre saúde e doença. Cremos, no entanto, que Canguilhem tem uma posição mais elaborada e se distancia do descontinuísmo absoluto de Bachelard, admitindo que as revoluções científicas, em suas palavras, "ñ̃o se fazem sem conservação da herança”. Seria então justa a sua crítica ao que chamou "vírus do precursor", tão comum em certas histórias das ciências e técnicas, para identificar quem primeiro criou uma dada teoria ou fez certa invenção? Nessa controvérsia cremos que a discussão não seria tanto a existência ou não de descontinuidades, mas sim em torno da natureza dessas.

Um tipo especial de descontinuidade metodológica foi introduzida nessa controvérsia pela epistemologia de Karl Popper, ao recusar a verificação da verdade científica com base no acúmulo indutivista de fatos particulares tidos como verdadeiros. Teorias poderiam vir a ser experimentalmente refutadas (ou "falseadas", na nomenclatura popperiana), mas enquanto não ocorresse essa descontinuidade, as ciências avançariam por meio de um acúmulo continuado de conjecturas no máximo plausíveis, mas inverificáveis. Popper tem em comum com Duhem a noção de ciência como busca de uma verdade inatingível, empreendimento sempre frustrado, porém nunca abandonado.

A clivagem causada pela controvérsia entre permanência e ruptura se intensificou a partir do surgimento em 1962 de A estrutura das revoluções cientificas, de Thomas Kuhn. Lançado dentro do projeto da "enciclopédia do movimento pela unidade da ciência" (por sua vez apoiado pelo positivismo lógico do Círculo de Viena), e retomando algumas conclusões de Koyré que Kuhn já havia assumido em $A$ revolução copernicana (1957), esse defendeu que a história das 
ciências é constituída por longos períodos de "ciência normal" ou paradigmática, entremeados por alguns períodos de crise que precedem as "revoluções científicas", encaradas como grandes saltos descontínuos. Durante a fase dita "normal", os cientistas se unem em torno de um consenso teórico-prático, que passa a ser confrontado por anomalias em determinado momento. Caso persistam anomalias insanáveis, o consenso se desfaria e surgiriam de forma não cumulativa o que seriam "revoluções científicas", exigindo uma reconstrução da visão de mundo.

O livro de Kuhn teve uma recepção inédita e sua influência ultrapassou as fronteiras da história das ciências. Espraiando-se também pela filosofia e sociologia, boa parte desse êxito se deve aos praticantes de diversos campos das ciências tanto naturais quanto humanas se reconhecerem antes na descrição kuhniana do que no falsificacionismo popperiano como praticantes de uma ciência paradigmaticamente normal. O descontinuísmo de Kuhn será retomado por autores como Althusser e Foucault, que vão justapô-lo à noção de corte epistemológico defendida por Bachelard.

É interessante notar como o anticontinuísmo de Kuhn veio reforçar a controvérsia entre externalismo e internalismo, invocando na disputa o tema da chamada "revolução científica" moderna, que teria ocorrido entre os séculos XVII a XVIII. O reforço teve também razões históricas conjunturais, pois a controvérsia se expandiu no período da guerra fria. O que estava então em jogo era qual deveria ser o papel do Estado na impulsão dada em direção a novas e desejadas "revoluções científicas": externalista, com forte participação estatal na política científica e tecnológica, como preconizavam posições mais à esquer$\mathrm{da}$, ou internalista, defendida pelo conservadorismo neoliberal, deixando que o "mercado" fosse o condutor. ${ }^{13}$

Nesse contexto, observamos que a expressão "estilo de pensamento" havia sido usada por um historiador que Kuhn considerou ter sido seu precursor, o polonês Ludwik Fleck, em sua obra de 1935 sobre a sífilis, Gênese e desenvolvimento de um fato científico. Para Fleck, entretanto, os estilos evoluiriam numa duração mais longa (ao contrário dos paradigmas de Kuhn ou das epistemes de Foucault). Nessa direção seria possível uma pluralidade de estilos, o que colocaria em xeque a noção tradicional de "método científico" no singular, ou seja, não haveria um método único e para sempre válido para as ciências, mas sim métodos plurais. ${ }^{14}$ Além disso, para Fleck o estilo de pensamento não é algo individual, mas coletivo, pois reflete um clima intelectual social. Nesses termos, a controvérsia do continuísmo versus descontinuísmo pode então ser repensada no modo como a introdução de novos estilos de pensamento convive com a relativa persistência de outros estilos.

Nesse ponto, é interessante recordar a visão iconoclasta de Paul Feyerabend, um "dadaísta" das ciências (rótulo que ele preferia ao de "anarquista") para quem não apenas não existiria um único "método científico", mas o avanço da ciência poderia se dar até por métodos considerados irracionais e, portanto, 
não científicos. Em Contra o método (1975), fugindo de uma sociologia avessa a controvérsias, e se distanciando tanto de Popper quanto de Kuhn, Feyerabend fez uma aproximação entre continuísmo e descontinuísmo que tem sido pouco visitada entre nós e muita caricaturada. Isso se deve provavelmente ao exagero das suas provocações a desafiar o establishment científico quando defende que na ciência, em suas palavras, "vale tudo", desde práticas mágicas ao curandeirismo. Em favor de Feyerabend, notamos que há toda uma tradição que resiste e teima em definir a ciência e seu funcionamento através de um reducionismo tautológico, que reside na pretensão de descrever um método, para explicar o que é um método. Incontáveis manuais ditos de "metodologia científica" se apoiam nesse recurso na tentativa de ensinar como proceder "cientificamente". Nesse ângulo da controvérsia do continuísmo opinamos que faria mais sentido um outro enfoque da crítica ao racionalismo, em que se poderia deixar uma porta aberta para a entrada de insights diretos na percepção do funcionamento da natureza, à maneira fenomenológica, isto é, sem a obrigatoriedade de formalismos lógico-matemáticos. ${ }^{15}$

Aqui vamos aproximar o plano das controvérsias historiográficas ao plano das controvérsias científicas. Podemos supor que há uma espécie de "matrizes de ideias" (ou Ur-ideias na terminologia filosófica alemã), que estão na base de conceitos científicos, que com o tempo são criticados e se transformam, mas permitindo estabelecer alguma continuidade das ideias numa pluralidade de contextos extracientíficos. Contra o positivismo lógico podemos, através da análise de casos históricos, reafirmar que o continuísmo no plano das ideias implicaria que não existe uma observação que emane dos "fatos" ou que seja "simples", pois mesmo a observação mais elementar seria o resultado de uma aprendizagem conforme o estilo de pensamento do observador, que não costuma ver além do que está predisposto a ver, e que além disso se enraíza no coletivo. Em outras palavras, a teoria ditaria o que será observado, e não vice-versa - conclusão que a muitos cientistas pareceria absurda, à primeira vista, mas que assim se revela na história das ciências.

\section{Whiggismo e historicismo}

A terceira controvérsia da historiografia da ciência que destacamos é a que opõe o historicismo ao whiggismo, termo às vezes traduzido como "presentismo", e para o qual propomos "triunfalismo", atentando à supremacia whiggista na historiografia autolaudatória vitoriana da segunda metade do século XIX.

Esse debate remete ao livro de Herbert Butterfield (1931), A interpretação whiggista da história, em que critica os historiadores que escrevem do ponto de vista dos vencedores, projetando o passado no tempo presente e produzindo uma história anacrônica, pela justificação determinista e glorificação do presente. Inicialmente dirigida à história política, o próprio Butterfield estendeu a crítica para o caso da história das ciências, quando essa se prende à narrativa heroica que vê na ciência do passado o anúncio das verdades da ciência atual, em decorrência da suposta ação inevitável do avanço científico (Butterfield, 1991). 
Nessa controvérsia historiográfica pensamos que há limites para a obsessão contra o anacronismo do tipo triunfalista (Jardine, 2000). Koyré, por exemplo, que também rejeitava a história triunfalista, admitia contudo que o historiador projete os interesses e valores de seu tempo para reconstruir o passado das ciências. Em suas palavras, com uma pitada de ironia, "é por isto que a história se renova e que nada muda tão depressa como o passado imutável” (Koyré, 1991). Nesses termos se valoriza a tese de que o presente é que ilumina o passado. Contra uma ideia de "objetividade" a todo custo, esse historiador da ciência propõe a necessidade de conhecer bem o presente para conseguir julgar o passado, admitindo expressar seus juízos de valor a respeito. ${ }^{16}$ Isso está em ressonância igualmente com Bachelard, que retoma Nietzsche, para quem o passado deve ser interpretado com a grande força do presente, ideia que ecoa também nos inícios da história das mentalidades na corrente dos Annales. Em consequência, o passado de uma ciência não se confundiria com a mesma ciência no passado, ou seja, o passado não estaria dado, mas admitiria ser reconstruído a partir de questões colocadas pela ciência contemporânea.

Um exame da produção internacional em história das ciências nos últimos 40 anos mostra um campo permanentemente entrecruzado por controvérsias do teor apontado.

Os adeptos de uma leitura kuhniana, por exemplo, segundo a qual o critério para decidir sobre a verdade de uma teoria científica é o consenso dos cientistas, se conjugaram com a influência do relativismo da linguagem do Wittgenstein das Investigações filosóficas. Isto abriu as portas para uma renovação da sociologia das ciências, bem ilustrada pela "Escola de Edimburgo", liderada por David Bloor a partir de meados da década de 1970. Bloor e Barry Barnes sintetizam o que chamam de "programa forte da sociologia das ciências" em torno de quatro princípios, igualmente plenos de controvérsias: causalidade, imparcialidade, simetria e reflexividade (Bloor et al., 1996). Como um dos efeitos dessa linha, surgiram nas universidades do mundo anglo-saxão os "SSS", ou Social Studies of Science, que provocaram um deslocamento do tradicional domínio da história das ciências pela física e astronomia para outras ciências, como a biologia, medicina, geologia e as ciências humanas. Olhar para as ciências como ancoradas na vida prática e local se tornou um dos objetivos dessa história, que incorporou em sua metodologia a teoria das redes sociais e a construção de fatos científicos por meio da negociação. ${ }^{17}$ Esse tipo de abordagem foi seguido no conhecido livro de Steven Shapin e Simon Schaffer, Leviatã e a bomba de vácuo (1985), em que mostram como a controvérsia sobre a existência do vácuo entre Boyle e Hobbes traduz por detrás das aparências uma série de oposições políticas, epistemológicas, retóricas e metafísicas.

Um aspecto relevante dessa tendência é que a escolha de objetos mais variados de estudo como museus, gabinetes de curiosidades ou jardins zoológicos mostrou que tanto a arquitetura desses locais quanto a disposição de objetos ne- 
les (inclusive instrumentos científicos) podem ser historicamente significativos. Também se dispensou atenção à formação das próprias disciplinas científicas, seus critérios aceitos de cientificidade, métodos de raciocínio e de estabelecimento de fatos e provas. Nessa direção se valorizaram ainda os estudos de ciências "nacionais" que, longe de defenderem aspectos nacionalistas, enfatizaram a maneira de praticar a ciência estabelecendo-se tradições locais de pesquisa. ${ }^{18}$

Amparados por perspectivas advindas da sociologia e antropologia, os Social Studies of Science têm conhecido uma crescente popularidade, que se verifica também nas universidades brasileiras pelo número de candidatos à pós-graduação que pretendem seguir nesta linha metodológica.

No entanto, essa tendência gerou novas controvérsias historiográficas, já que por ela a história das ciências tem se orientado para objetos cada vez mais restritos e efềmeros, constituindo frequentemente uma micro-história sem conteúdo epistemológico. ${ }^{19}$ Levado ao extremo, o antitriunfalismo conduziu às teses de uma sociologia das ciências, para quem o historiador deve se comportar como se a verdade ou falsidade de uma tese científica do passado não tivessem ainda sido estabelecidas. $\mathrm{O}$ estudo de Bruno Latour sobre o debate da geração espontânea entre Pasteur e Pouchet é um conhecido exemplo de apresentar a história do ponto de vista do vencido (Latour, 1996). Não estaria assim a História das Ciências recaindo em outro tipo de positivismo, no qual a reconstrução da atividade científica decorreria automaticamente da identificação dos conflitos locais de grupos e suas disputas pelo poder? O risco que comporta essa tendência à micro-história é ignorar que, apesar do interesse, justificativa e utilidade que possam ter esses estudos, as ciências tenderiam a ultrapassar as condições locais, contingentes e particulares de seu aparecimento.

\section{A superação do problema: dialética das controvérsias científicas}

O levantamento analítico antecedente mostra alguns impasses metodológicos. Julgamos que há um caminho que não tem sido suficientemente trilhado e que poderia contribuir para avançar o conhecimento historiográfico das ciências: trata-se de valorizar o papel dialético das controvérsias científicas, e que poderia ser frutífero tanto para o fazer científico quanto para sua historiografia.

Não consideramos superada a controvérsia do dualismo entre internalismo e externalismo, e acentuamos que a primazia para se entender o passado das ciências deve ser constituída pelas múltiplas contribuições externas, em que a atividade científica está imersa no tecido social e econômico e sem esquecer o sentido amplo de "externo", que inclui as ideias filosóficas e o ambiente cultural. Evidentemente também devemos estar atentos às vias internas de desenvolvimento de uma ciência.

Desse ponto de partida decorre que aceitemos que as ideologias permeiam o desenvolvimento científico e que isto não seria bom ou mau em si, mas simplesmente inevitável. Uma ideologia científica não é necessariamente uma falsa ciência ou uma superstição - por exemplo, o modelo ptolomaico é perfeita- 
mente científico e assim foi usado; a sua validade e praticidade é que entram em questão, a partir de certa escala dos fenômenos examinados. Referimo-nos naturalmente à mudança de referencial para descrição do movimento planetário, que pode ser arbitrariamente escolhido como a Terra ou o Sol.

A construção de teorias que permitam um conhecimento cada vez mais aprofundado da natureza e suas aplicações científicas tem sido um empreendimento de duração relativamente longa. O avanço científico não é em curto prazo inevitável exatamente devido à existência contínua de controvérsias científicas, o que nos faz reconhecer a existência de múltiplos caminhos e métodos que podem impulsionar, mas também fazer regredir o conhecimento. No processo somos levados a deixar de lado a rígida demarcação de fronteiras nítidas entre prática (techné) e teoria (epistéme), assim como entre ciências puras e aplicadas, passando a valorizar mais as aproximações do que seus distanciamentos.

Percebemos assim que há semelhanças entre as controvérsias da face historiográfica das ciências e o núcleo interno de controvérsias científicas. Para esclarecer melhor nossa proposta podemos exemplificá-la com a questão do continuísmo e que se evidencia numa grande quantidade de teorias científicas. É a antiga questão da continuidade: a natureza dá saltos? O debate aparece seja na física clássica, seja na física atômica. Na biologia ele se traduz no clássico problema do surgimento de novas espécies, fenômeno descontínuo que não se conseguiu observar na natureza nem em laboratório. Em geologia a transformação ligada à formação de montanhas, continentes, mares e outros fenômenos passou de uma teoria explicativa de evolução catastrofista para a de uma lenta transformação continuísta. Poderíamos acrescentar muito mais controvérsias que envolvem de uma maneira ou de outra a continuidade.

O problema da continuidade na natureza tem uma homologia com as transformações históricas em geral. Nessas a questão aparece nas discussões sobre revoluções socioeconômicas e outras mudanças - industriais, culturais etc. - suscitando a dúvida sobre a essência e a continuada permanência de tais rupturas nas estruturas sociais e econômicas mais profundas da sociedade, inclusive daquelas que adentram profundezas psicológicas - qual é o caráter das transformações naturais e humanas em geral?

Para que as controvérsias científicas possam ser visitadas com maior proveito pelos historiadores da ciência, sugerimos que, além de fazê-lo virando os olhos para o passado, se investigue se elas se mantêm no presente, mesmo mudando de roupagem. Assim se evidenciaria a dialética histórica em que teorias e seus protagonistas que foram aparentemente vencidos fornecem subsídios para releituras e novas sínteses, tanto do lado historiográfico quanto científico.

Nossa proposta suscita ainda uma indagação: como deve o historiador se portar ante o entendimento simplista da ciência e da história das ciências que predomina na educação e nos meios de divulgação? O mais comum é que na 
mídia uma notícia sobre ciência ignore totalmente a existência de controvérsias e a apresente com base no argumento de autoridade, scientia dixit. A resposta para isso seria mostrar como a história das ciências é uma história de controvérsias e que a entendendo assim, podemos compreender melhor como a ciência funciona no presente: não como acúmulo de certezas inquestionáveis, mas sim como um processo de busca que recomenda a humildade em meio a incertezas.

Defendemos, portanto, que a exposição e narrativa das controvérsias lança uma história que busca a inserção social, econômica e cultural do conhecimento, permitindo-nos escapar de padrões positivistas de diversos matizes. Em especial, acreditamos que isso teria um grande atrativo para o ensino de ciências naturais em todos os níveis e para o desenvolvimento dessas próprias ciências. Nessa possibilidade de aplicação, a história das ciências teria importância para a metodologia do trabalho científico porque permitiria vislumbrar possibilidades de desenvolvimento interno futuro. As aparentes certezas de hoje seriam relativizadas pela inevitabilidade de controvérsias, em permanente criação e recriação.

Do ponto de vista epistemológico, quer-nos parecer que olhar para a dialética das controvérsias científicas como metodologia historiográfica equivale a reconhecer que o verdadeiro motor do desenvolvimento científico não está em noções apenas de método, mas sim na existência permanente de sínteses geradas pelas controvérsias, pelos erros e acertos na ciência. Nesta abordagem dificilmente reconhecemos um período de ciência "normal", pois a ênfase nas controvérsias ressalta a importância epistemológica e histórica de que a ciência esteja sempre em crise, pois é assim que brotam novos resultados. A discordância e falta de consenso são essenciais, pois funcionam para que não haja estagnação do conhecimento científico, distinguindo-se de outras atividades humanas em que a ortodoxia possa ser a regra. Sem esse entendimento dialético, a ciência acabaria por sucumbir à intolerância porque seria dominada por dogmas e paradigmas, como uma religião.

Dessa maneira acreditamos que a história das ciências poderia funcionar como ponte para transpor o famigerado abismo entre "duas culturas", entre humanidades e ciências naturais, e realizar a verdadeira interdisciplinaridade e a intradisciplinaridade, tão almejadas, mas pouco praticadas. Se há algo que a ciência possa aprender da história será entender seu avanço como resultado da dialética das suas controvérsias.

\section{Notas}

1 Para essas primícias, ver Motoyama (1974); Academia de Ciências do Estado de São Paulo, Anais do Simpósio sobre Filosofia da Ciência, Aciesp n.12, 1978; Anais do Simpósio sobre História e Filosofia da Ciência, Aciesp n.23, 1979.

2 É o caso do filósofo brasileiro Marcelo Dascal (formado na Escola Politécnica da USP, mas radicado em Israel) e seu grupo. Ver Perspectives on Theory of Controversies and the 
Ethics of Communication: Explorations of Marcelo Dascal's Contributions to Philosophy (Doordrecht: Springer, 2014).

3 Refiro-me, entre outros, a títulos como História da medicina, em que se vê a origem e o progresso desta arte, de Daniel Le Clerc (1702), a História das matemáticas, de Jean-Étienne Montucla (1758), ou ainda a História e estado atual da eletricidade, de Joseph Priestley (1767), tratado que influenciou notável e diretamente as pesquisas científicas desse campo durante um bom tempo.

4 Biografias científicas, é claro, fazem parte da história da ciência, mas aqui deve-se distinguir a investigação historiográfica crítica, como preconizavam os Annales, e para a qual um destaque é a biografia exemplar de Agassi (1971), em contraste com obras de divulgação, como Einstein, sua vida, seu universo, de Isaacson ( 2007).

5 Cf. Robert Fox discorreu em "Mapping the universe of knowledge: internationalism and national interest in modern science", 2014 Fall Conference, Chemical Heritage Foundation (Filadélfia). Notas pessoais.

6 Declaração de Georges Sarton ao fundar a revista Isis em 1913 (ainda hoje a publicação central da disciplina, levada para os Estados Unidos quando seu idealizador emigrou durante a Primeira Guerra, e onde organizaria a Sociedade Americana de História da Ciência). Sarton vê esse desenvolvimento sob a óptica interessante de que o progresso das ciências é o único progresso contínuo e inegável a ponto de permitir comparar toda a humanidade a um único homem, como aliás afirmava Blaise Pascal (1989) em seu Tratado do Vácuo (1647).

7 Esse diagnóstico do irracionalismo numa atividade racional foi exposto com argúcia por Formam (1983) em "A cultura de Weimar, a causalidade e a teoria quântica, 1918-1927"; Uma análise mais global do processo se encontra em Herman (1999). A partir de 1991 procuramos apontar como sair desse imbroglio do irracional numa atividade racional em textos que levaram à colaboração permanente nas pesquisas do núcleo do Centro de Filosofia da Ciência da Universidade de Lisboa (cf. Croca et al., 2017).

8 O texto se encontra em Gama (1993).

9 A tese de Merton foi exposta em 1936 nas páginas do número inicial de Osiris, outra publicação fundada por Georges Sarton e companheira de Isis. Para a controvérsia ver por exemplo Brooke (2003) e Numbers ( 2009).

10 Veja-se essa influência de Zilsel em Conner (2005).

11 A influência de Koyré se estendeu a historiadores importantes e ainda bastante lidos hoje, como Bernard Cohen, Rupert Hall, Herbert Butterfield, Alistair Crombie e Charles Gillispie, levando além disso à redescoberta de Edwin Burtt (1991), que em seu As bases metafísicos da ciência moderna enfatizou a matematização platônica do pensamento de Galileu e sobretudo o que aquele autor definiu como o "positivismo de Newton".

12 Ver, a respeito, a lúcida "Introdução" de Pierre Thuillier (1994) ao seu De Arquimedes a Einstein.

13 É a época em que se destacam as posições neoliberais de Michael Polanyi, em $A$ lógica da liberdade.

14 É também a conclusão a que chega Ruy Pérez (2003). 
15 É como associamos os avanços científicos da Naturphilosophie, principalmente as descobertas de Oersted e Ritter no eletromagnetismo. Também Poincaré acentuou a importância desse fenômeno na física e matemática.

16 Isto é recorrente também em Canguilhem, que manifesta um “anti-anti-whiggismo”, cf. Bowker e Latour (1987).

17 A difusão dessa tendência é ilustrada pela crescente influência tanto da revista Social Studies of Science (fundada em 1971) quanto de Science in Context (fundada em 1988).

18 Um exemplo é o estudo que compara a ciência francesa, mais abstrata e centralizada, com a inglesa, mais empírica e pública, feito por NYE (1986.

19 O caso bem conhecido de pesquisa de construção social dos fatos científicos é o livro $A$ vida de laboratório, de Bruno Latour e Steve Woolgar (1997), lançado em 1979. Para Foucault, tampouco a ciência trata da luta pela verdade, já que não haveria verdade absoluta e, nem mesmo, verdade relativa.

\section{Referências}

AGASSI, J. Towards an historiography of science. Gravenhage: Mouton, 1963. Faraday as a Natural Philosopher. Chicago: University of Chicago, 1971.

BACHELARD, G. A formação do espirito científico. Rio de Janeiro: Contraponto, 1996.

BACON, F. O progresso do conhecimento. São Paulo: Editora Unesp, 2007.

BLOOR, D.; BARNES, B.; HENRY, J. Scientific knowledge. Chicago: Chicago U. P. 1996.

BOWKER. G.; LATOUR, B. A booming discipline short of discipline: Social Studies of Science in France, Social Studies of Science, n.17, 1987.

BRAUNSTEIN, J.-F. L'histoire des sciences. Paris: Vrin, 2008.

BROOKE, J. H. Ciência e Religião. Algumas perspectivas históricas. Porto: Porto Ed., 2003.

BURTT, E. As bases metafísicas da ciência moderna. Brasília: Editora UnB, 1991.

BUTTERFIELD, H. As origens da ciência moderna. Lisboa: Ed. 70, 1991.

CANGUILHEM, G. O normal e o patológico. Rio de Janeiro: Forense Universitária, 1995.

CONNER C. A people's history of Science. Miners, midwives and "low mechanicks". New York: Nation Books, 2005.

CROCA, J.; CASTRO, P.; GATTA, M. Euritmia, complexidade e racionalidade numa perspectiva interdisciplinar. Lisboa: CFCUL, 2017.

DUHEM, P. A teoria física: seu objeto e sua estrutura. Rio de Janeiro: Editora da Uerj, 2014.

FEYERABEND, P. Contra o método. Rio de Janeiro: Francisco Alves, 1989.

FLECK, L. Genesis and development of a scientific fact. Chicago; Chicago U.P., 1981.

FORMAN, P. A cultura de Weimar, a causalidade e a teoria quântica, 1918-1927. Cadernos de História e Filosofia da Ciência (CLE/Unicamp), Suplemento 2, 1983. 
GAMA, R. (Org.) Ciência e Técnica (antologia de textos históricos). São Paulo: T. A. Queiroz, 1993.

GAVROGLU, K. O passado das ciências como história. Porto: Porto Ed., 2007.

HERMAN, A. A ideia de decadência na história ocidental. Rio de Janeiro: Record, 1999.

ISAACSON, W. Einstein, sua vida, seu universo, São Paulo: Cia. das Letras, 2007.

JARDINE, N. Uses and abuses of anachronism in the history of the sciences. History of Science, v.XXXVIII, 2000.

KOYRÉ, A. Perspectivas da História das Ciências. In: Estudos de história do pensamento científico. Rio de Janeiro: Forense Universitária, 1991.

. Do mundo fechado ao universo infinito. Rio de Janeiro: Forense, 2001.

KUHN, T. A estrutura das revoluções cientificas. São Paulo: Perspectiva, 1975.

LATOUR, B. Pasteur e Pouchet: heterogênese da história das ciências. In: SERRES, M. (Dir.) Elementos para uma história das ciências. Lisboa: Terramar, 1996. v.III.

Ciência em ação. São Paulo: Editora Unesp, 2000.

LATOUR, B.; WOOLGAR, S. A vida de laboratório. Janeiro: Relume Dumará, 1997.

MAGALHÃES, G. Ciência e ideologia. Uma excursão à história em torno da ideia de progresso. São Paulo: Intermeios, 2017.

MERTON, R. Science, technology \& society in 17th-century England. New York: Harper, 1970.

MOTOYAMA, S. (Org.) História da Ciência, perspectiva científica. Revista de História (USP), v.XLVI, 1974.

NUMBERS, R. (Ed.) Galileo goes to jail and other myths about science and religion Cambridge: Harvard U., 2009.

NYE, M. J. Science in the provinces, scientific communities and provincial leadership in France, 1860-1930. Berkeley: University of California, 1986.

PASCAL, B. Tratado do Vácuo (1647). Cadernos de História e Filosofia da Ciência (CLE/Unicamp), série 2, v.1, 1989.

PÉREZ, R. Existe el método científico? México: Fondo de Cultura Económica, 2003.

POINCARÉ, H. O valor da ciência. Rio de Janeiro: Contraponto, 2000.

POLANYI, M. A lógica da liberdade. Rio de Janeiro: Topbooks, 2003.

ROSSI, P. Os filósofos e as máquinas. São Paulo: Cia. das Letras, 1989.

SHAPIN, S.; SCHAFFER, S. Leviathan and the air-pump. Hobbes, Boyle and the experimental life. Princeton: Princeton University Press, 2011.

THUILLIER, P. De Arquimedes a Einstein. Rio de Janeiro: Jorge Zahar, 1994.

ZILSEL, E. The social origins of modern science. Dordrecht: Kluwer, 2003. 
RESUMO - Este artigo descreve os impasses epistemológicos e metodológicos que caracterizam a pouca interação entre os historiadores da ciência no debate sobre suas linhas de pesquisa e afiliações. A influência positivista persistente tem impedido a valorização das controvérsias científicas e a historiografia da ciência se ressente dessa ausência, em detrimento de uma compreensão de como funciona a ciência.

PALAVRAS-CHAVE: Historiografia da ciência, Positivismo, Controvérsias.

ABSTRACT - This article describes the epistemological and methodological impasses that characterize the lack of interaction among historians of Science in the debate about their lines of research and affiliations. The enduring Positivist influence has precluded recognizing the value of scientific controversies, and the history of Science suffers this absence, which damages the perception of how science works.

KEYWORDS: Historiography of science, Positivism, Controversies.

Gildo Magalhães é professor titular do Departamento de História e diretor do Centro Interunidades de Ciências da USP. Fellow da Smithsonian Institution em Washington, DC, e da Chemical Heritage Foundation, em Filadélfia (Pensilvânia, EUA).

@ - gildomsantos@hotmail.com

Recebido em 25.3.2018 e aceito em 26.3.2018.

${ }^{\text {I }}$ Departamento de História, Faculdade de Filosofia, Letras e Ciências Humansa, Universidade de São Paulo, São Paulo, São Paulo, Brasil. 
